\title{
Alterations in glutathione system in adult and pup rat brains following chronic aluminum exposure
}

\begin{abstract}
Glutathione is a major regulator of the redox equilibrium in cells, so its deficit weakens the tissue resistance to oxidants. Several pathologies that affect the nervous system involve oxidative stress, possibly associated with the decrease of glutathione content. The nervous system is particularly susceptible to oxidative insults and is therefore dependent on its glutathione content, especially during development stage, where brain metabolism and growth are maximal. To study the involvement of glutathione in brain redox homeostasis, we set up an experimental model of aluminum (Al) neurotoxicity (AICl3+ $100 \mathrm{mg} / \mathrm{kg} \mathrm{b} . \mathrm{wt}$ ) for eight weeks to both developed and developing rats. In the developing group exposure of $\mathrm{Al}$ for 60 days was done post natally, 21 days to feeding mother (lactation period) and 39 days to pup rats. Similar dose for eight weeks were given to adult rats. The result showed a statistically significant $(P<0.01)$ decrease in Total glutathione, reduced glutathione and oxidized glutathione in both cerebrum and cerebellum region of pup brains. A similar decrease was observed in adult group. Also, aluminum exposure resulted in significant decrease in ATPase activity in both the regions of the brain of developing and developed rat brain. Thus the present study indicates that aluminum exposure $(100 \mathrm{mg} /$ $\mathrm{kg} \mathrm{b.wt)} \mathrm{to} \mathrm{both} \mathrm{adult} \mathrm{and} \mathrm{pup} \mathrm{rat} \mathrm{results} \mathrm{in} \mathrm{the} \mathrm{decline} \mathrm{of}$ glutathione system which alters the redox ratio significantly. Further, aluminum exposure also decreases the ATPase activity which in turn could affect the glutathione synthesis.
\end{abstract}

Key words: Aluminum, developing rat brain, glutathione, neurotoxicity

\section{INTRODUCTION}

Glutathione is the brain master's antioxidant and protect neurons from the harmful effects of free radicals. Many neurological and psychiatric disease processes are characterized by abnormalities in glutathione metabolism and antioxidant defenses. ${ }^{[1]}$ GSH (g-glutamylcysteinylglycine), is a sulfhydryl (-SH) antioxidant, antitoxin and enzyme cofactor which is an important component of the cellular detoxification of reactive oxygen species. ${ }^{[2]}$ Being water soluble it is found mainly in the cell cytosol and other aqueous phases of the living system and thus constitute one of the most important ${ }^{[3-5]}$ intracellular antioxidants. Additionally it also plays an important role in brain development and apoptosis.

Generation of reactive oxygen species (free radicals) and oxidative damage are an important cause of neuron death. Chemicals that cause toxicity to certain brain cells are known to decrease the cerebral glutathione levels. Brain is particularly susceptible to free radical attack because it generates more oxidative by-products per gram of tissue than any other organ. Additionally, being highly oxygenated and rich in unsaturated lipid it is vulnerable to endogenous oxygen radical production and peroxidation. ${ }^{[6]}$ Brain regions rich in catecholamines \{adrenaline, noradrenaline and dopamine can spontaneously break down (auto-oxidize) to free radicals or become metabolized to radicals by the endogenous enzymes known as monoamine oxidases. One such region is the substantia nigra, where a connection has been established between antioxidant depletion (including GSH) and tissue degeneration..$^{[7]}$ Developing brain also posses a greater challenge to oxidative damage since it is still at a morphological, biochemical and functional immaturity in the early post natal life. Further developing brain is subject to high oxygen tension and lacks a functional blood brain anti-oxidant protection that is
Priya Anand, B. Nehru Department of Biophysics, Punjab University, Chandigarh - 160 014, India

For correspondence: Dr. Bimla Nehru, Department of Biophysics, Punjab University, Chandigarh - 160014, India. E-mail: bnehru@pu.ac.in

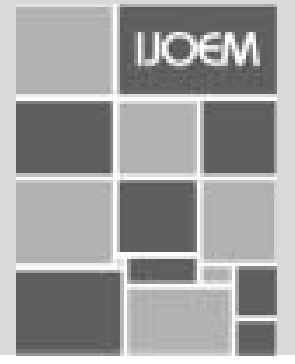


important in the development of the brain. The distribution and cell-specific expression of the various antioxidant enzymes in immature brain and after postnatal brain insult has not been documented. ${ }^{[8,9]}$

The present experiment was designed to study glutathione redox system in adults and pup rats brain following the neurotoxic manifestations of aluminum (Al) in the form of $\mathrm{AlCl}_{3+}$ exposure for a period of 8 weeks in dose of $100 \mathrm{mg} / \mathrm{kg}$ b.wt. Al commonly found in the environment is easily encountered by humans in food, water, dust, air, drugs and medical treatment. $\mathrm{Al}$ is considered to be a neurotoxic metal and $\mathrm{Al}$ exposure may be an etiological factor of several neurological disease such as Parkinson's' disease, Alzheimer's disease and amyotrophic lateral sclerosis. The molecular mechanism involved in Al neurotoxicity has yet not been clarified, but it has been suggested that $\mathrm{Al}$ at dose (100 mg/kg b.wt.) alters the oxidative homeostasis, glucose metabolism and neurotransmission processes thus impairing the cognitive and memory functions. ${ }^{[10]}$

\section{MATERIALS AND METHODS}

\section{Experimental design}

Twenty six mature, healthy rats of Sprague Dawley strain were procured from the central animal house of Panjab University, Chandigarh, which were equally divided in two groups (12 each) one developing (group A) and one developed group (group B). The animals were 6 months old and their body weight was in the range 150-200 gm They were acclimatized under hygienic conditions and were fed on standard pelleted rat feed (Hindustan Lever Ltd., Mumbai, India) and water ad-libitum. The diet had adequate quantity of micronutrients as well as macronutrients. The animals were kept and cared for and during all stages in compliance with the applicable guidelines and regulations of the institute. Group A was further divided into 2 subgroup (6 animals each subgroup), Subgroup I served as control and were given free access to water and diet. Subgroup II animals received Aluminum chloride (dissolved in water) by an oral gavage daily with dose of $100 \mathrm{mg} / \mathrm{kg}$ b.wt of elemental aluminum for a period of 8 weeks. Similarly in group B animals subgroup III serve as control and subgroup IV received aluminum (100 $\mathrm{mg} / \mathrm{kg}$ bwt) as aluminum chloride (21 days to feeding mothers and 39 days to pups) orally for 8 weeks.

Breeding of animals were done in the animal house of Panjab university by keeping the ratio of male: females: $3: 2$, in the plastic cages. The females were checked daily for vaginal plaque and the day on which the vaginal plaque was seen, was marked as day one. The female rats were separated, divided into 2 subgroups and placed in separate cage for the gestation period. The rat litter obtained from the parents, were allowed to survive on their mother's milk. The mother's of subgroup III served as control and IV were administered $\mathrm{AlCl}_{3}$. The litter size of the control subgroup was 8-10 rats which were decreased to 5-6 rats after Al treatment. Weekly weight changes were recorded and the dose was adjusted accordingly. The rats were monitored for their health, general behavior and daily diet intake. Aluminum chloride and other reagents were purchased from Merck company.

For the various biochemical estimations, the animals of various groups were sacrificed by decapitation. Their brain was removed immediately and various regions of brain i.e. cerebral cortex and cerebellum were dissected out, rinsed in ice cold water normal saline and blotted dry. All processes were carried out in cold conditions. The two brain regions were homogenized in $10 \mathrm{mM}$ phosphate buffer saline $(10 \%$ $\mathrm{w} \backslash \mathrm{v})$ of $\mathrm{pH} 7.4$.

\section{Glutathione reduced (GSH)}

Estimation of GSH was performed in the tissue homogenate by the method of Moron ${ }^{[1]}$ et al, 1979. In this method 5, 5dithiobis 2-nitrobenzoic acid (DTNB) is reduced by -SH groups to form 1 mole of 2-nitro-5-mercaptobenzoic acid per mole of SH. The nitro mercaptobenzoic acid anion released has intense yellow color and can be used to measure -SH groups at $412 \mathrm{~nm}$.

\section{Total glutathione content}

The analysis was done by the method of Zahler and Cleland, ${ }^{[12]}$ 1968. This method is based on the reduction with dithioerythritol and determination of the resulting monothiols with DTNB in the presence of arsenite. The arsenite forms a light complex with dithiols but not with monothiols. The absorbance resulting from the monothiols is determined by extrapolation of the linear plot of the curve of the time of addition of DTNB and subtractions of a blank value for a sample containing no disulfide.

\section{Oxidized glutathione}

Oxidized glutathione was quantitated by subtraction the values of the glutathione reduced from total glutathione levels.

\section{Redox ratio (GSH/GSSG)}

Redox ratio was determined for all the four groups by taking the ratio of reduced glutathione/oxidized glutathione.

\section{ATPase $\mathrm{Mg}^{+2}$ dependent}

ATPase $\mathrm{Mg}^{+2}$ dependent activities were measured by the method of Kielleny ${ }^{[13]}$ et al, 1955. Enzyme activity was expressed as $\mathrm{mg}$ of $\mathrm{P}_{\mathrm{i}}$ released $/ \mathrm{mg}$ protein $/ \mathrm{min}$.

\section{Estimations of protein}

Protein contents in various samples were estimation by 
method of Lowry, ${ }^{[14]} 1961$.

\section{Statistical analysis}

The above data were expressed as mean $+\mathrm{SD}$ and difference between the control and $\mathrm{Al}$ treated animals were determined by student's t-test.

\section{RESULTS}

After the aluminum chloride exposure for 60 days to adult animals a significant decrease in the total glutathione content was observed. The decrease was $25.1 \%$ in cerebrum and $60.9 \%$ in cerebellum region. The reduced glutathione content was also decreased significantly $(P<0.001)$. The decrease was $39.7 \%$ in cerebrum and $20 \%$ in cerebellum. The oxidized glutathione content was slightly decreased in aluminum treated group as compared to normal control. The decrease (7.5\%) was observed in cerebrum region of the brain. However, an increase was observed in cerebellum region of the brain after Al exposure. The ratio of GSH/GSSG was decreased in both the regions. The decrease was $34.7 \%$ in cerebrum and $33.6 \%$ in cerebellum regions.

Similarly in pup rats total glutathione level was decreased after $\mathrm{Al}$ exposure was $56.2 \%$ in cerebrum and $60.9 \%$ in cerebellum. Al treatment significantly decreased the reduced glutathione enzyme content in both the regions; decrease was $37.9 \%$ in cerebrum and $28.8 \%$ in cerebellum. Oxidized glutathione enzyme content was also decreased significantly $(P<0.001)$, the decrease was $60.9 \%$ in cerebrum and $69.8 \%$ in cerebellum. However in pups group after aluminum exposure the Redox ratio was significantly increased in both the regions of the brain. The increase was $76.9 \%$ in cerebrum and $161.8 \%$ in cerebellum region.

After aluminum treatment to adult group in the form of $\mathrm{AlCl}_{3^{\prime}}$ causes a significant reduction $(P<0.001)$ in the ATPase enzyme activity both in cerebrum (i.e., 19.8\%) and cerebellar (11.6\%) regions, Similarly, in pups a significant decrease was observed $(P<0.001)$ after aluminum exposure as compared to normal control group. Decrease was observed in both the regions (i.e., approx. $42 \%$ ).

\section{DISCUSSION}

Epidemiological experimental as well as clinical studies have indicated strong association between al accumulation and several neurological disorders such as Alzheimer's disease, Down syndrome, ${ }^{[15]}$ etc. A search for the understanding of the cellular and molecular basis of aluminum toxicity has stimulated many experimental studies. In the present in vivo studies an attempt has been made to investigate the potential of $\mathrm{Al}$ as a neurotoxicant.
Following aluminum exposure at $100 \mathrm{mg} / \mathrm{kgb} . w \mathrm{wt}$ /day given orally, no significant reduction in the body weight as well as brain weight was found in adult groups, when compared to their respective controls, suggesting that the dose was well tolerated by the experimental animals [Table 1]. Baydar ${ }^{[16]} e t$ al also recorded no change in body weight and relative organs weights except for the adrenal glands in adult rats. The weight gain in $\mathrm{Al}$ treated group was however slower.

In contrast the weight gain in treated groups of pups administered aluminum $(100 \mathrm{mg} / \mathrm{kg}$ bwt/ day, 21 days to feeding mothers and 39 days to pups) was slower than in the controls over the treatment period. The litter size was also decreased following Al exposure. Several factors could explain this decrease in weight gain which includes the untoward effect of $\mathrm{Al}$ on general health status or its interference with the hormonal status and/or protein synthesis. Domingo ${ }^{[17]} e t$ al established that oral Al exposure during pregnancy causes syndrome including growth retardation, delayed ossification and malformation at $\mathrm{Al}$ doses that also lead reduced maternal weight gain.

Brain has several characteristics that make it susceptible to free radical mediated injury. Brain lipid are highly enriched in polyunsaturated fatty acids and many regions of brain such as substantia nigra and striatum has high concentration of iron, additionally brain is critically dependent on aerobic metabolism and the mitochondrial respiratory activity is higher than in many other tissues, increasing the risk of free radical "leak" from the mitochondria. Aluminum exposures accentuate this free radical surge for several unknown reasons. Several reports point out the free radical damage following Al exposure. ${ }^{[18]}$ Studies on aluminum toxicity mechanism have pointed out a biphasic action where on one hand it behaves as a pro-oxidant in presence of iron generating free radicals and other as an inhibitor of the antioxidant enzyme system..$^{[19,20]}$

Glutathione is an important component of the cellular

Table 1: Effects of aluminum, on body weight and brain weight in grams

\begin{tabular}{lcc}
\hline Group A: Adults & & \\
\hline Groups & Body weight & Brain weight \\
\hline Control & $225 \pm 25$ & $1.676 \pm 0.07$ \\
Aluminium & $224 \pm 20$ & $1.679 \pm 0.21$ \\
Group B: Pups & & \\
\hline Groups & Body weight & Brain weight \\
\hline Control & $125 \pm 0.00$ & $1.742 \pm 0.007$ \\
Aluminium & $120 \pm 2.88^{* *}(1.3 \%)^{*}$ & $1.439 \pm 0.08^{* * *}(17.4 \%)^{*}$ \\
\hline
\end{tabular}

Statistical analysis: Values are mean \pm S.D. of 6-7 determinations, Values in bracket are $\%$ increase $(+)$ or $\%$ decrease $(-),{ }^{*} P<0.05,{ }^{* *} P<0.01,{ }^{* * *} P<0.001$ : Treatment w.r.t. Control 
detoxification of reactive oxygen species. ${ }^{[7]}$ In humans, glutathione is found in all tissues and protects against potential damage from wastes and toxins. Glutathione exists in two forms one as antioxidant "reduced glutathione" conventionally called glutathione (GSH) and other oxidized form known as glutathione disulfide or GSSG. The GSSG/ GSH ratio is a sensitive indicator of oxidative stress [Table 2]. Thus the intracellular GSH status appears to be a sensitive indicator of the cell's overall health and of its ability to resist toxic challenge. ${ }^{[21]}$

In the present study, adult rats exposed to the aluminum dose (100 mg/kg b.wt) for 60 days, registered a highly significant decrease in the level of total glutathione and GSSG compared to control animals [Table 3]. Additionally significant decreased in the GSH and redox ratio was observed in aluminum exposed rats as compared to control animals. Studies of Katyal ${ }^{[22]}$ indicated that exposure of aluminum significantly decreased the brain glutathione levels though on changes were seen in the liver.

As already stated that, ATP act as a co-substrate for both the enzymes involved in GSH synthesis. In aluminum toxic conditions, aluminum form complex with ATP (Al-ATP) as it has strong affinity for phosphate ion, which is $10^{7}$ times stronger than $\mathrm{Mg}^{2+}$ ion. ${ }^{[23]}$ Therefore, it can be hypothesized that less availability of ATP has hindered the synthesis of GSH by altering its synthesis from $\gamma$-Glutamylcysteine $(\gamma$ GluCys) synthetase and glutathione synthetase, enzymes involved in GSH synthesis.

A similar result was found in rat pups groups: Aluminum exposure significantly decreased $(P<0.001)$ the total glutathione, GSSG, GSH and redox status in both cerebrum and cerebellum of the brain.

However the exposure of aluminum to pups was more detrimental as compared to adult rats on two accounts one a porous BBB and secondly deficiency of endogenous glutathione systems. The BBB is formed by brain capillary endothelial cells and in the late embryonic and early postnatal period, theses cells respond to inducing factors found in the brain environment by adopting a set of defined characteristics. ${ }^{[24]}$ Thus presence of $\mathrm{Al}$ at the post-natal stage might affect the formation of $\mathrm{BBB}$ in pups, resulting in higher exposure to the neurotoxic metal compared to the same dose given to adults group.

In our present study, aluminum exposure to pup and adult rats significantly decreased the $\mathrm{Mg}^{2+}$ ATPase enzyme activity both in cerebrum and cerebellum region of the brain as compared to the normal controls. However, decreased in the

Table 2: Alterations in total glutathione reduced glutathione, oxidised GSH, redox status, Mg +2 ATPase in the cerebrum and cerebellum region of pup rats brain following aluminum exposure

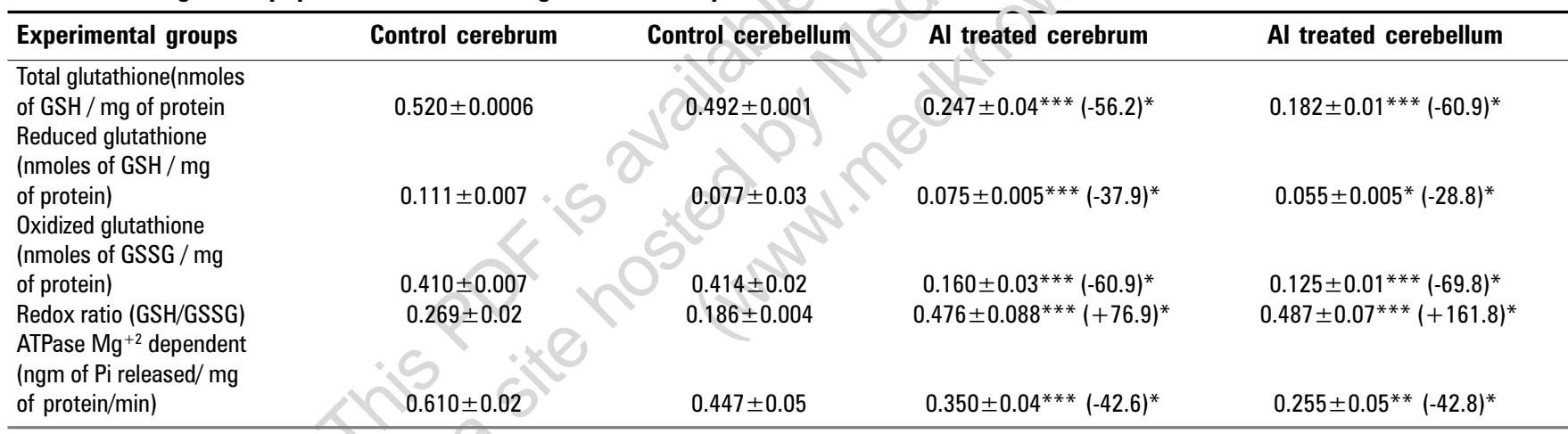

Statistical analysis: Values are mean + S.D. of $5-6$ determinations, values in bracket are $\%$ increase $(+)$ or $\%$ decrease $(-),{ }^{*} P<0.05,{ }^{* *} P<0.01,{ }^{* * *} P<0.001$ : Treatment w.r.t. control, Al - Aluminum, Figures in parentheses are percentage.

Table 3: Alterations in total glutathione reduced glutathione, oxidized GSH, redox status, $\mathrm{mg}+2$ ATPase in the cerebrum and cerebellum region of adult rats brain following aluminum exposure

\begin{tabular}{lcccc}
\hline Experimental groups & Control cerebrum & Control cerebellum & Al-treated cerebrum & Al treated cerebellum \\
\hline $\begin{array}{l}\text { Total glutathione (nmoles of } \\
\text { GSH } / \mathrm{mg} \text { of protein }\end{array}$ & $0.442 \pm 0.01$ & $0.429 \pm 0.02$ & $0.331 \pm 0.01^{* * *}(-25.1)^{*}$ & $0.182+0.01^{* * *}(-60.9)^{*}$ \\
$\begin{array}{l}\text { Reduced glutathione (nmoles } \\
\text { of GSH / mg of protein) }\end{array}$ & $0.244 \pm 0.002$ & $0.297 \pm 0.02$ & $0.147 \pm 0.001^{* * *}(-39.7)^{*}$ & $0.343+0.03^{* * *}(-20.0)^{*}$ \\
$\begin{array}{l}\text { Oxidized glutathione(nmoles } \\
\text { of GSSG / mg of protein) }\end{array}$ & $0.198 \pm 0.01$ & $0.132 \pm 0.02$ & $0.183 \pm 0.01^{*}(-7.5)^{*}$ & $0.139+0.03^{*}(+5.3)^{*}$ \\
$\begin{array}{l}\text { Redox ratio (GSH/GSSG) } \\
\text { ATPase Mg+2 dependent (ngm } \\
\text { of Pi released/ mg of protein/min }\end{array}$ & $1.23 \pm 0.09$ & $2.313 \pm 0.5$ & $0.803 \pm 0.09^{* * *}(-34.7)^{*}$ & $1.534+0.3^{*}(-33.6)^{*}$ \\
\hline
\end{tabular}

Statistical analysis: Values are mean + S.D. of 5-6 determinations, Values in bracket are $\%$ increase $(+)$ or $\%$ decrease $(-),{ }^{*} P<0.05,{ }^{* *} P<0.01,{ }^{* * *} P<0.001$ : Treatment w.r.t. control, $\mathrm{Al}$ - Aluminum, Figures in parentheses are percentage. 
enzyme activity was higher in cerebrum and cerebellum region of the pup rats (approx 42\%) as compared to the adult's rats. The $\left(\mathrm{Na}^{+} / \mathrm{K}^{+}\right)$ATPase (EC 3.6.3.9) is the largest protein complex in the family of P-type ATPases expressed in all living organisms. It is essential for the generation and maintenance of $\mathrm{Na}^{+}$and $\mathrm{K}^{+}$gradients between the intracellular and extracellular milieux, a prerequisite for basic cellular homeostasis and for functions of specialized tissues. Failure of the $\left(\mathrm{Na}^{+} / \mathrm{K}^{+}\right)$ATPase has been implicated in the pathophysiology of neurodegenerative diseases. ${ }^{[25]}$ It is likely that the decrease in $\mathrm{Mg}^{2+}$ ATPase might have resulted from competitive binding of $\mathrm{Al}^{+3}$ to the enzyme active site. It is known that $\mathrm{Al}^{3+}$ binds almost $10^{7}$ times more strongly to ATP${ }^{4}$ then does $\mathrm{Mg}^{2+}$ and less than nanomolar amounts of $\mathrm{Al}^{3+}$ can compete with $\mathrm{Mg}^{2+}$ for phosphate sites, which have resulted in decreased activity of enzyme. In addition, it can also be assumed that, $\mathrm{Al}$ is known to combine with ATP (adenosine triphosphate) to form Al-ATP complex and thus a decrease the ATP concentration. ${ }^{[26-28]}$

\section{CONCLUSION}

Thus the present study indicates that aluminum exposure (100 mg/kg b.wt) to both adult and pup rat results in the decline of glutathione system which alters the redox ratio significantly. Further, aluminum exposure also decreases the ATPase activity which in turn could affect the glutathione synthesis.

\section{REFERENCES}

1. Fonnum F, Lock EA. The contribution of excito toxicity, glutathione depletion and DNA repair in chemically induced injury to neurons: Exemplified with toxic effects on cerebellar granule cells. J Neurochem 2004;88:513-31.

2. Cooper AJ. Glutathione in the brain: Disorders of Glutathione metabolism. In the Molecular and Genetic Basis of Neurological Disease. Rosenberg RN, Prusiner SB, Dimauro S, Barchi RL, Kunk LM, editors. Butterworth-Heinemann: Boston; 1970. p. 1195-230.

3. Meister A. Glutathione metabolism and transport. In: Nygaard OF, Simic MG, editors. Radioprotectors and Anticarcinogens. Academic Press: New York, NY; 1976.

4. Kidd PM. Natural antioxidants the first line of defense. In: Kidd PM, Huber W. Living with the AIDS virus: A strategy for long-term survival. PMK Biomedical-Nutritional Consulting: Albany, California; 1991. p. 115-42.

5. Lomaestro BM, Malone M. Glutathione in health and disease: Pharmacotherapeutic issues. Ann Pharmacother 1995;29:1263-73.

6. Lohr JB, Browning JA. Free radical involvement in neuropsychiatric illnesses. Psychopharmacol Bull 1995;31:159-65.

7. Graham DG. Oxidative pathways for catecholamines in the genesis of neuromelanin and cytotoxic quinones. Mol Pharmacol 1978;14:63343.

8. Beiswanger CM, Diegmann MH, Novak RF, Philbert MA, Graessle TL, Reuhl KR, et al. Developmental changes in the cellular distribution of glutathione and glutathione S-transferases in the murine nervous system. Neurotoxicology Fall 1995;16:425-40.

9. Dringen R, Gutterer JM, Hirrlinger J. Glutathione metabolism in brain, Metabolic interaction between astrocytes and neurons in the defense against reactive oxygen species. Eur J Biochem 2000;267:4912-6.

10. Nehru B, Anand P. Oxidative damage following chronic aluminium exposure in adult and pup rat brains. J Trace Elem Med Biol 2005;19:203-8.

11. Moron MS, Depierre JW, Mannervik B. Levels of glutathione, glutathione reductase and glutathione S-transferase activities in rat lung and liver. Biochem Biophys Acta 1979;582:67-78.

12. Zahler WL, Cleland WW. A specific and sensitive Assay for disulfides. J Biol Chem 1968;243:716-9.

13. Kielley NW. Mitochondrial ATPase In: Methods in Enzymology Vol 2. Colowick SP, Kaplan NO, editors. Academic Press: New York; 1995. p. 583.

14. Lowry OH, Rosebrough NJ, Farr AL, Randall RJ. Protein measurement with the Follin-phenol reagent. J Biol Chem 1951;193:265-75.

15. Exley C, Korchazhkina O. The association of aluminium and beta amyloid in Alzheimer's disease. In: Aluminium and Alzheimer's Disease: The Science that Describes the Link. Elsevier Science: Amsterdam, The Netherlands; 2001. p. 421-33.

16. Baydar T, Papp A, Aydin A, Nagymajtenyi L, Schulz H, Isimer A, et al. Accumulation of aluminum in rat brain. Biol Trace Element Res 2003;92:231-44.

17. Domingo JL. Reproductive and developmental toxicity of aluminium: A review. Neurotoxicol Tetratol 1995;17:515-21.

18. Ogasawara Y, Ohata E, Sakamoto T, Ishii K, Takahashi H, Tanabe S. A model of aluminum exposure associated with lipid peroxidation in rat brain. Biol Trace Elem Res 2003;96:191-201.

19. Yoshino M, Ito M, Haneda M, Tsubouchi R, Murakami K, Prooxidant action of aluminum ion-stimulation of iron-mediated lipid peroxidation by aluminum, Biometals 1999;12:237-40.

20. Oteiza PI, Fraga CG, Keen CL, Aluminum has both oxidant and antioxidant effects in mouse brain membranes. Arch Biochem Biophys 1993;300:517-21.

21. Schulz JB, Lindenau J, Seyfried J, Dichgans J. Glutathione, oxidative stress and neurodegeneration. Eur J Biochem 2000;267:4904-11.

22. Katyal R, Desigan B, Sodhi CP, Ojha S. Oral aluminum administration and oxidative injury. Biol Trace Elem Res 1997;57:125-30.

23. Martin RB. The chemistry of Aluminum as related to biology and medicine. Clin Chem 1986;32:1797-806.

24. Rubin LL, Staddon JM. The cell biology of the blood brain barrier. Ann Rev Neurosci 1999;22:11-28.

25. Yu SP. $\mathrm{Na}^{+}, \mathrm{K}^{+}$-ATPase: The new face of an old player in pathogenesis and apoptotic/hybrid cell death. Biochem Pharmacol 2003;66:1601-9.

26. Schlichting I, Reinstein J. pH influences fluoride coordination number of the AlFx phosphoryl transfer transition state analog. Nat Struct Biol 1999;6:721-3.

27. Lai JC, Guest JF, Leung TK, Lim L, Davison AN. The effects of cadmium, manganese and aluminium on sodium-potassium-activated and magnesium-activated adenosine triphosphatase activity and choline uptake in rat brain synaptosomes. Biochem Pharmacol 1980;29:1416.

28. Silva VS, Gonçalves PP. The inhibitory effect of aluminium on the $\left(\mathrm{Na}^{+} / \mathrm{K}^{+}\right)$ATPase activity of rat brain cortex synaptosomes. J Inorg Biochem 2003;97:143-50.

\section{Source of Support: This work was supported by grants from Department of Biophysics, Panjab University, Chandigarh. Conflict of Interest: None declared.}

